OPEN ACCESS

Edited by:

Kamal Dua,

University of Technology

Sydney, Australia

Reviewed by: Keshav Raj Paudel,

University of Technology

Sydney, Australia

Qingliang Wang,

Third Affiliated Hospital of Sun Yat-sen

University, China

*Correspondence:

Feng Pan

uh_fengpan@hust.edu.cn

tThese authors have contributed equally to this work

Specialty section

This article was submitted to

Pulmonary Medicine,

a section of the journal

Frontiers in Medicine

Received: 07 August 2021 Accepted: 17 November 2021 Published: 15 December 2021

Citation:

Li L, Wu X, Liu D, Zhang W, Yang L and Pan $F$ (2021) Preliminary

Exploration of Transpedal Lymphangiography With High-Dose Ethiodized Oil Application in the

Treatment of Postoperative

Chylothorax. Front. Med. 8:754781.

doi: 10.3389/fmed.2021.754781

\section{Preliminary Exploration of Transpedal Lymphangiography With High-Dose Ethiodized Oil Application in the Treatment of Postoperative Chylothorax}

\author{
Lin $\mathrm{Li}^{1,2 \dagger}$, Xin $\mathrm{Wu}^{1,2 \dagger}$, Dehan Liu ${ }^{1,2}$, Wei Zhang ${ }^{1,2}$, Lian Yang ${ }^{1,2}$ and Feng Pan ${ }^{1,2 *}$ \\ ${ }^{1}$ Department of Radiology, Union Hospital, Tongji Medical College, Huazhong University of Science and Technology, \\ Wuhan, China, ${ }^{2}$ Hubei Province Key Laboratory of Molecular Imaging, Wuhan, China
}

Objective: To preliminarily explore the safety and effectiveness of transpedal lymphangiography (TL) with high-dose ethiodized oil application (>20 ml) in the treatment of high-output postoperative chylothorax.

Methods: From 1 July 2020 to 1 July 2021, a total of 7 patients with high-flow postoperative chylothorax $(>1,000 \mathrm{ml} / \mathrm{d}$ ) were retrospectively reviewed in a single center. Clinical data, including surgery types, technical and treatment success of $T L$, and adverse events of $T L$, were collected and analyzed.

Results: Seven patients ( 5 cases of non-small cell lung cancer; 2 cases of esophageal carcinoma) with a median age of 62 years (range: 30-70 years) occurred postoperative chylothorax after tumor resection with mediastinal lymphadenectomy. All patients received conservative treatment including total parenteral nutrition and somatostatin administration for a median of 20 days (range: 15-31 days) that failed to cure the chylothorax, so TL was performed as a salvage. Before TL, the median daily chyle output was 1,500 ml/day (range: 1,100-2,000 ml/day). The technical success rate of TL was $100 \%$ (7/7), with the median volume of ethiodized oil of $27.6 \mathrm{ml}$ (range: 21.2-30.0 ml) injected in TL. Ruptured thoracic duct was identified in 5 patients (5/7, $71 \%$ ) in fluoroscopy and chest CT after TL. The treatment success rate of TL was $86 \%$ (6/7). In 6 patients, the thoracic drainage was removed after a median of 7 days (range: 4-13 days) from TL performance. No adverse event of TL was reported.

Conclusion: Transpedal lymphangiography with high-dose ethiodized oil application $(>20 \mathrm{ml})$ is a feasible, safe, and effective modality for the treatment of high-flow (>1,000 $\mathrm{ml} /$ day) postoperative chylothorax.

Keywords: lymphangiography, ethiodized oil, chylothorax, postoperative complications, thoracic neoplasms 


\section{INTRODUCTION}

Postoperative chylothorax is a rare and refractory complication after thoracic surgery. It can lead to a large amount of nutrient loss, including protein, triglycerides, and other substances, resulting in electrolyte imbalance, malnutrition, and severe infection (1-3). Especially for patients with high-output chylothorax $(>1,000 \mathrm{ml} / \mathrm{d})$, if treatment is ineffective, lifethreatening sequelae might occur with a mortality rate of up to $50 \%(1-3)$. Conservative treatment (e.g., total parenteral nutrition, somatostatin, etc.) is the first-line choice for postoperative chylothorax (3-6). However, there are some defects when treating patients with high chyle output, such as unsatisfactory efficiency and long treatment period with poor tolerability (3-6). Surgical repair, as a salvage treatment after the failure of conservative treatment, has a high occurrence rate of secondary surgery-related complications and the risk of death (up to 38 and $25 \%$, respectively) (4-7).

The conventional transpedal lymphangiography (TL) is a classic diagnosis method for postoperative chylothorax with a therapeutical effect. The viscous ethiodized oil injected in TL can embolize the lymphatic leakage site (8). In literature, TL was reported with an overall treatment success rate of over $50 \%$ and a complication rate of $<3 \%$ when treating postoperative chylothorax $(5,7,9)$. Compared to surgical repair, TL is minimally invasive and can be tolerated by critically ill patients. Therefore, TL holds the potential as second-line management where conservative treatment fails. In conventional TL, it was empirically recommended that ethiodized oil should not exceed $20 \mathrm{ml}(5,8-11)$. Nevertheless, this recommended ethiodized oil dose may be insufficient for treating high-dose postoperative chylothorax because of the poor treatment efficiency rate of $35 \%$ $(5,10)$. Increasing the ethiodized oil dose in TL may benefit the leakage embolization and improve treatment efficiency. So far, it still lacks objective evidence on the safety or clinical efficacy of TL treatment with high-dose ethiodized oil ( $>20 \mathrm{ml}$ ) application in TL. This retrospective study preliminarily explored the safety and effectiveness of TL with high-dose ethiodized oil application $(>20 \mathrm{ml})$ in the treatment of high-output postoperative chylothorax when conservative treatment failed.

\section{MATERIALS AND METHODS}

\section{Definitions and Standards}

The clinical and pathological staging of malignant tumors is based on the 8th edition of TNM Classification of Malignant Tumors $(12,13)$. Diagnostic criteria for postoperative chylothorax: 1. Exclusion of other postoperative complications of pleural effusion, such as malignant pleural effusion, inflammatory exudation, etc.; 2. Milk-like pleural drainage (Figure 1A), triglyceride level of drainage fluid higher than 110 $\mathrm{mg} / \mathrm{dL}$, or positive chylomicrons test $(11,14,15)$. The technical success of TL is defined as the opacification of the thoracic lymphatic system under fluoroscopy $(11,16,17)$. The treatment success of TL is defined as immediate cessation or gradual reduction of lymphatic leakage after TL leading to the removal of thoracic drainage within 2 weeks without the requirement of other treatments $(6,11,18,19)$. The lymphatic duct leakage is identified as definite ethiodized oil extravasation out from thoracic duct visualized in dynamic fluoroscopy, or the ectopic presence of the ethiodized oil in the pleural space observed in chest CT after TL (20).

\section{Patients}

This study retrospectively collected a total of 7 patients with postoperative chylothorax after thoracic surgery admitted to this center from July 2020 to July 2021. The TL was indicated following: 1 . fulfill the postoperative chylothorax diagnostic criteria; 2 . after conservative treatment including total parenteral nutrition and somatostatin for more than 2 weeks, no progressive decrease of the thoracic chyle output; 3 . after multidisciplinary team discussion (including physicians from departments of respiratory medicine, thoracic surgery, interventional radiology, and anesthesiology), it was decided to give priority to TL treatment; 4. obtain written informed consent of the patient. Contraindications for TL treatment follow: severe pulmonary dysfunction identified by pulmonary function test, pulmonary arteriovenous malformations/fistula, and right-to-left shunt heart disease (11).

\section{TL Procedure}

After dermal sterilization, $1 \mathrm{ml}$ of a 1:3 mixture of methylthioninium chloride $(20 \mathrm{mg} / 2 \mathrm{ml}$, JUMPCAN pharmaceutical group Co., LTD, Jizhou, China) and 1\% lidocaine was injected into each interdigital space on either left or right foot to dye the dorsal lymphatic vessels (Figure 1B). After $20 \mathrm{~min}$, incise the dorsal skin of the foot under local anesthesia to separate the subcutaneous lymphatic vessel (Figures 1C,D). Afterwards, puncture the target lymphatic vessel by using a 26-G trocar needle (Jerui, WEGO, Weihai) (Figure 1E) and fix it with suture and sterile tapes (Figure 1F). Then, connect the trocar with an infusion pump (WZS-50F6, Zhejiang Smiths Medical, Hangzhou, China) to conduct the ethiodized oil injection (super-fluid ethiodized oil, Hengrui, Jiangsu, China). The pressure restriction and infusion velocity of the pump was set as a "High" model and $0.4 \mathrm{ml} / \mathrm{min}$, respectively. From then, fluoroscopy (Artis Zee, Siemens Healthineers, Erlangen, Germany) was performed every 2-5 min to dynamically observe the opacification of the lymphatic vessels from the foot to the left jugular vein angle. Unlike the previous reports in which the operator ceased the injection after 6 to $12 \mathrm{ml}$ of ethiodized oil application no matter whether the thoracic duct was opacified, the endpoint of injection in this study was the visualization of the left jugular vein angle (20-22). Then, the needle was removed and the dorsal wound of the foot was sutured. The chest CT (SOMATON emotion 16, Siemens, Germany) was immediately performed (filling phase) to identify the specific lymphatic leakage site with 3-dimensional reconstruction (scan parameters: $120 \mathrm{kv}$, adaptive current, and B30f iterative reconstruction) (20). If there is no lymphatic fistula, the same chest CT examination will be re-performed $24 \mathrm{~h}$ later (nodal phase) for further diagnosis (20). 

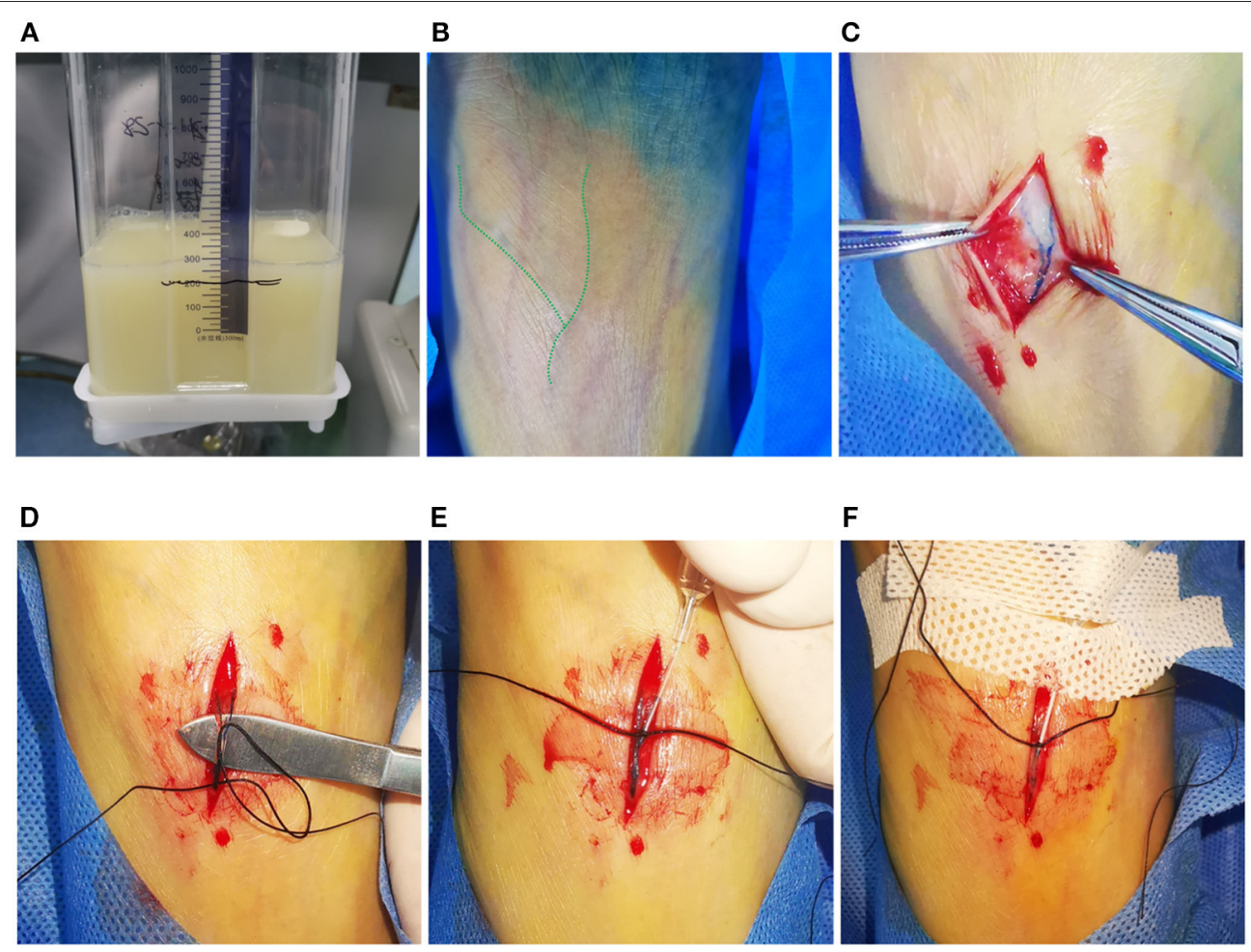

E
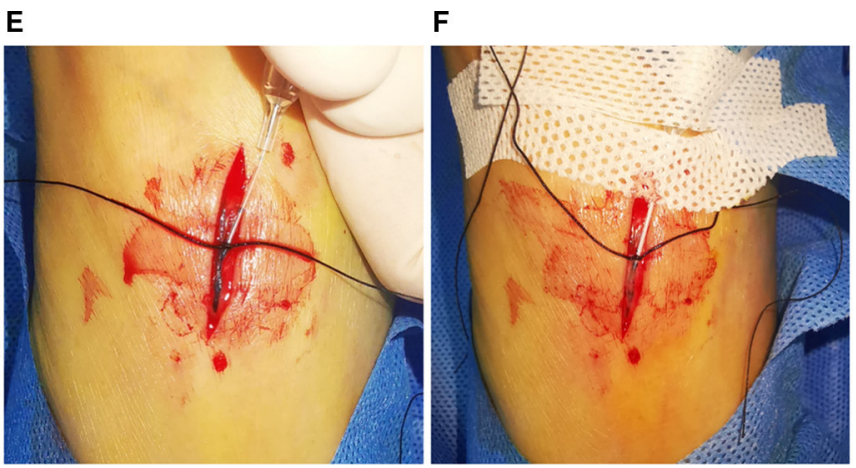

FIGURE 1 | Typical visual demonstration of chylothorax drainage and cannulation of pedal lymphatic vessel in TL procedure. (A) Typical visual demonstration of chylothorax drainage. (B) 20 min after dye injection between interdigital spaces, superficial lymphatic vessels could be observed with tinted blue color (alongside the green dash line) on dorsal foot. (C) After incision, subcutaneous lymphatic vessels can be clearly found with deep blue color. (D) Meticulous separation of the target lymphatic vessels. (E) Manual puncture of the lymphatic vessel by using a 26-G intravenous needle. (F) After fixation of the trocar by suture and sterile tape, the ethiodized oil can be injected afterwards.

\section{Study Goals}

Record the time of the lymphatic opacification at the levels of the knee joint space, upper femoral head, L5/Th12/Th5 vertebrae, and left jugular veinous angle from start of ethiodized oil injection during TL. Identify the technical success of TL and thoracic duct rupture in fluoroscopy and following chest CT. Evaluate the treatment success and adverse event of TL from the institutional electronic records.

\section{Statistical Analysis}

The data in this study were analyzed using Excel 2019 (Microsoft, USA). Quantitative and counting data are presented as median with range and count with percentages of the total, respectively. Since no group comparison is performed, only descriptive analysis is used.

\section{RESULTS}

The median age of 7 patients (4 males and 3 females) was 62 years (range: $30-70$ years). Two and 5 patients were diagnosed with esophageal carcinoma and non-small cell lung carcinoma, respectively. All patients underwent surgical tumor resection with mediastinal lymphadenectomy. After surgery, postoperative chylothorax occurred in 5 patients on the right side and 2 on the left side. TL treatment was performed at a median of 20 days (range: 15-31 days) after surgery. The median daily chyle output before TL was 1,500 $\mathrm{ml} /$ day (range: 1,100-2,000 $\mathrm{ml} /$ day). The details are shown in Table 1.

The technical success of TL was $100 \%(7 / 7)$. The median volume of ethiodized oil injected in TL was $27.6 \mathrm{ml}$ (range: $21.2-$ $30.0 \mathrm{ml}$ ) (Table 2). The median time of lymphatic opacification at the levels of knee joint space, upper femoral head, L5 vertebra, Th12 vertebra, Th5 vertebra, and the left jugular venous angle from the start of ethiodized oil injection were $4 \mathrm{~min}$ (range: 3-7 $\mathrm{min}$ ) and $10 \mathrm{~min}$ (range: 9-12 $\mathrm{min}$ ), $22 \mathrm{~min}$ (range: 15$34 \mathrm{~min}$ ), $42 \mathrm{~min}$ (range: $33-51 \mathrm{~min}$ ), $52 \mathrm{~min}$ (range: $47-62 \mathrm{~min}$ ) and $69 \mathrm{~min}$ (53-75 min) (Table 2; Figure 2). Lymphatic duct leakage, including definite ethiodized oil extravasation out from thoracic duct in dynamic fluoroscopy and the ectopic presence of the ethiodized oil in the pleural space in chest CT after TL, was identified in 5 patients $(5 / 7,71 \%)$ (Table 2; Figure 2). No Adverse event of TL was recorded.

After TL, 6 patients experienced a progressive decrease of the daily chyle output. The median time for removing the thoracic drainage after TL was 7 days (range: $4-13$ days). The treatment success rate of TL was $86 \%$ (6/7). One patient without significant reduction of daily chyle output after TL underwent further percutaneous afferent lymphatic vessel sclerotherapy (ALVS) on the 8th day after TL, who was cured later (11). 
TABLE 1 | Basic characteristics.

\begin{tabular}{|c|c|c|c|c|c|c|c|c|c|c|c|}
\hline $\begin{array}{l}\text { Patient } \\
\text { ID }\end{array}$ & Sex & $\begin{array}{c}\text { Age } \\
\text { (years) }\end{array}$ & Diagnosis & $\begin{array}{l}\text { Clinical } \\
\text { staging }\end{array}$ & Surgery & $\begin{array}{l}\text { Mediastinal } \\
\text { lymphadenectomy }\end{array}$ & $\begin{array}{l}\text { Location of the } \\
\text { tumor }\end{array}$ & $\begin{array}{l}\text { Postoperative } \\
\text { pathological } \\
\text { staging }\end{array}$ & $\begin{array}{l}\text { Pathological } \\
\text { diagnosis }\end{array}$ & $\begin{array}{l}\text { Side of } \\
\text { chylothorax }\end{array}$ & $\begin{array}{l}\text { Daily chyle } \\
\text { output } \\
\text { before TL } \\
\text { (ml/d) }\end{array}$ \\
\hline 1 & Female & 62 & $\begin{array}{l}\text { Non-small cell } \\
\text { lung cancer }\end{array}$ & IA2 (1bNOMO) & $\begin{array}{l}\text { Anatomical } \\
\text { pulmonary } \\
\text { resection }\end{array}$ & Yes & $\begin{array}{l}\text { Upper lobe of right } \\
\text { lung }\end{array}$ & IA2 (1bNOMO) & $\begin{array}{l}\text { Invasive } \\
\text { adenocarcinoma }\end{array}$ & Right & 1,500 \\
\hline 2 & Male & 64 & $\begin{array}{l}\text { Non-small cell } \\
\text { lung cancer }\end{array}$ & IA2 (1bNOMO) & $\begin{array}{l}\text { Anatomical } \\
\text { pulmonary } \\
\text { resection }\end{array}$ & Yes & $\begin{array}{l}\text { Upper lobe of right } \\
\text { lung }\end{array}$ & IA2 (1bNOMO) & $\begin{array}{l}\text { Invasive } \\
\text { adenocarcinoma }\end{array}$ & Right & 1,100 \\
\hline 3 & Female & 30 & $\begin{array}{l}\text { Non-small cell } \\
\text { lung cancer }\end{array}$ & IA2 (1bNOMO) & $\begin{array}{l}\text { Anatomical } \\
\text { pulmonary } \\
\text { resection }\end{array}$ & Yes & $\begin{array}{l}\text { Lower lobe of right } \\
\text { lung }\end{array}$ & IA2 (1bNOMO) & $\begin{array}{l}\text { Invasive } \\
\text { adenocarcinoma }\end{array}$ & Right & 2,000 \\
\hline 4 & Male & 62 & $\begin{array}{l}\text { Non-small cell } \\
\text { lung cancer }\end{array}$ & IA2 (1bNOMO) & $\begin{array}{l}\text { Anatomical } \\
\text { pulmonary } \\
\text { resection }\end{array}$ & Yes & $\begin{array}{l}\text { Upper lobe of left } \\
\text { lung }\end{array}$ & IA2 (1bNOMO) & $\begin{array}{l}\text { Invasive } \\
\text { adenocarcinoma }\end{array}$ & Right & 1,500 \\
\hline 5 & Female & 70 & $\begin{array}{l}\text { Non-small cell } \\
\text { lung cancer }\end{array}$ & IA2 (1bNOMO) & $\begin{array}{l}\text { Sublobar } \\
\text { resection }\end{array}$ & Yes & $\begin{array}{l}\text { Upper lobe of right } \\
\text { lung }\end{array}$ & IA2 (1bNOMO) & $\begin{array}{l}\text { Invasive } \\
\text { adenocarcinoma }\end{array}$ & Left & 1,200 \\
\hline 6 & Male & 64 & $\begin{array}{l}\text { Esophageal } \\
\text { carcinoma }\end{array}$ & ॥ (T2NOMO) & Esophagectomy & Yes & $\begin{array}{l}\text { Middle third of } \\
\text { esophagus }\end{array}$ & IB (T2NOMOG1) & $\begin{array}{l}\text { Well- } \\
\text { differentiated } \\
\text { squamous cell } \\
\text { carcinoma }\end{array}$ & Left & 1,700 \\
\hline 7 & Male & 56 & $\begin{array}{l}\text { Esophageal } \\
\text { carcinoma }\end{array}$ & ॥ (T2NOMO) & Esophagectomy & Yes & $\begin{array}{l}\text { Middle third of } \\
\text { esophagus }\end{array}$ & ॥A (T2NOMOG2) & $\begin{array}{l}\text { Moderately } \\
\text { differentiated } \\
\text { squamous cell } \\
\text { carcinoma }\end{array}$ & Right & 2,000 \\
\hline $\begin{array}{l}\text { Median } \\
\text { (minimum- } \\
\text { maximum) }\end{array}$ & & $\begin{array}{c}62 \\
(30-70)\end{array}$ & & & & & & & & & $\begin{array}{c}1,500 \\
(1,100-2,000)\end{array}$ \\
\hline
\end{tabular}

The clinical and pathological staging are based on the 8th edition of TNM Classification of Malignant Tumors (12, 13). TL, transpedal lymphangiography. 


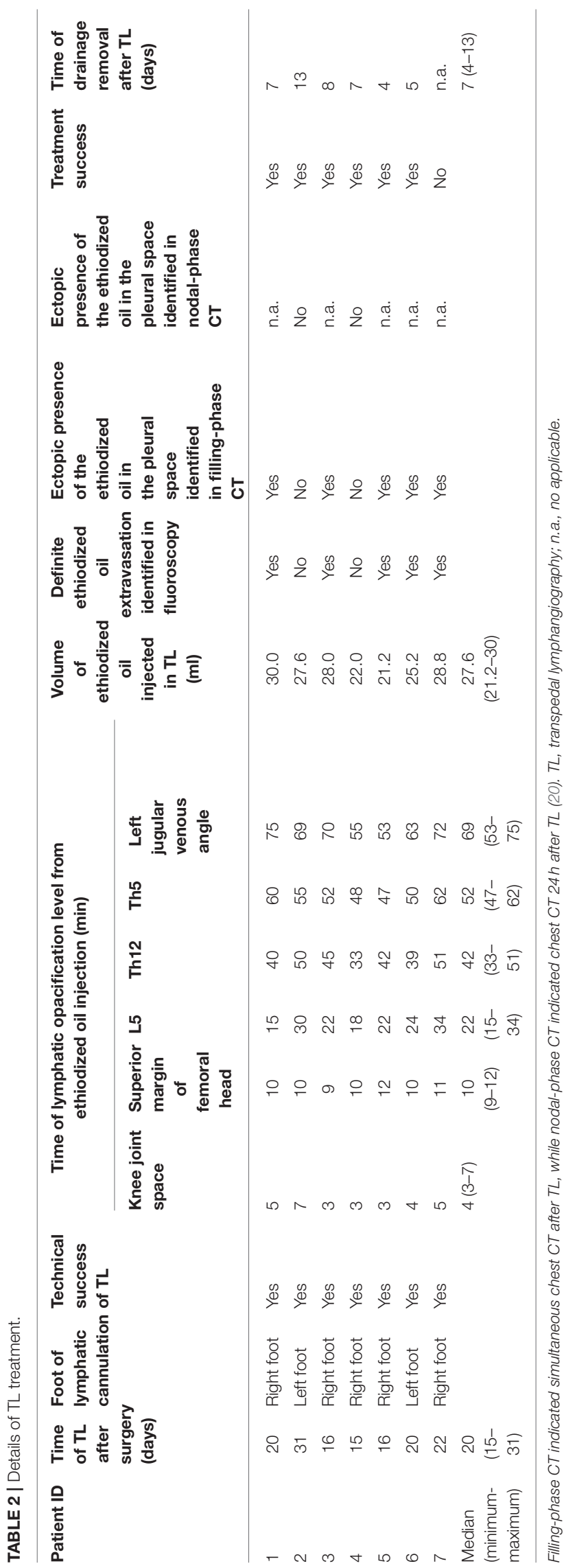

\section{DISCUSSION}

In this retrospective study, 5 and 2 patients had chylothorax complications after lung cancer and esophageal cancer resection, respectively, with a daily chyle output of more than $1,000 \mathrm{ml} / \mathrm{d}$. After 15-31 days of ineffective conservative treatment, all patients received TL treatment with high-dose ethiodized oil application $(>20 \mathrm{ml})$. The technical success was achieved in all patients, with the median volume of ethiodized oil injected in TL of $27.6 \mathrm{ml}$. The treatment success rate of TL was $86 \%$ (6/7). No Adverse event of TL was reported.

So far, TL has been increasingly used to manage postoperative chylothorax with a technical success rate of $95-100 \%(5,6,8,9$, 23). Except for the embolization effect, ethiodized oil can induce sterile inflammation at the fistula, beneficial for subsequent histological repair (8). However, the traditional manual injection of ethiodized oil in TL was unstable with the velocity between 0.2 and $0.5 \mathrm{ml} / \mathrm{min}$ and tiring over hours' operation $(8,21)$. So, we improved the injection method by connecting an infusion pump commonly used, replacing the primordial handy injection. This simple technical improvement can stabilize the injection pressure and velocity. Moreover, it benefits the standardization of TL procedure for the research purpose. For instance, the mean time of lymphatic visualization at different targets can be statistically analyzed: $10 \mathrm{~min}$ for superior margin of femoral head (groin region), $42 \mathrm{~min}$ for Th12 (cistern chyli region), and $69 \mathrm{~min}$ for left jugular venous angle (whole thoracic duct).

In previous studies, the ethiodized oil usage in TL was mostly around $10 \mathrm{ml}(5,8-11,18,20-22)$. But after accomplishment of injection, the ethiodized oil probably only reached pelvic or abdominal lymphatic vessels, so interventionalists always needed to monitor for more than $4 \mathrm{~h}$ until the ethiodized oil flowed into the thoracic duct $(8,11,20-22)$. With the increase of ethiodized oil dose to more than $20 \mathrm{ml}$, we can visualize the left jugular vein angle as the endpoint of ethiodized oil injection, resulting in a more reliable thoracic duct embolization. It explained why the treatment success rate of TL for the high-flow postoperative chylothorax reached $86 \%(6 / 7)$ in our cohort, which was higher than $35 \%$ in previous reports $(5,10)$. Similarly, a recent report also showed that high-dose ethiodized oil $(>40 \mathrm{ml}$ ) application in intranodal lymphangiography (INL) was feasible and safe (24). It achieved a treatment success rate of $83 \%$ without any adverse event for the treatment of high-flow postoperative chylothorax, similar to our findings (24). However, we need to point out: in INL, part of the ethiodized oil was wasted because of the extravasation from the punctured lymph node, so we can't confirm how much of the ethiodized oil genuinely entered the lymphatic system $(8,24)$. But in TL, the needle was fixed with suture resulting in a more reliable ethiodized oil injection without any waste, resulting in less usage of ethiodized oil than INL (21).

Nevertheless, the interventionalists need to pay attention to the risk of ectopic embolism caused by ethiodized oil. Although most ethiodized oil in TL is filtered and gradually resolved in lymph nodes, a small portion of ethiodized oil in the lymphatic vessels can enter the subclavian vein into the pulmonary circulation, which was filtered by a regular 


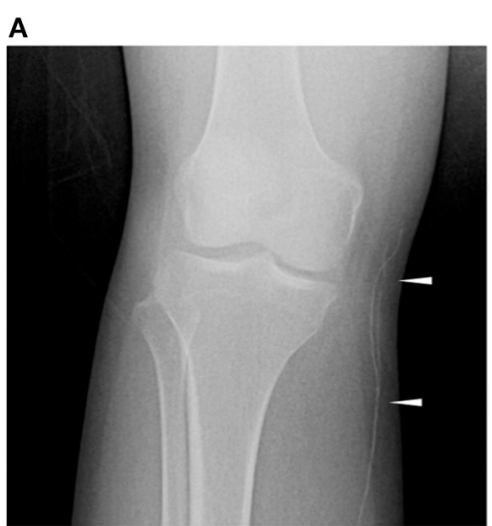

D

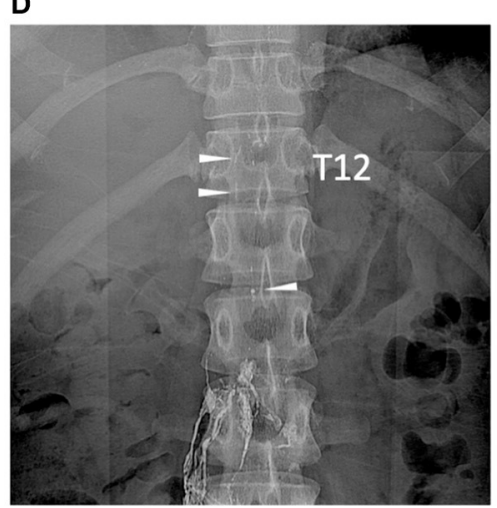

G

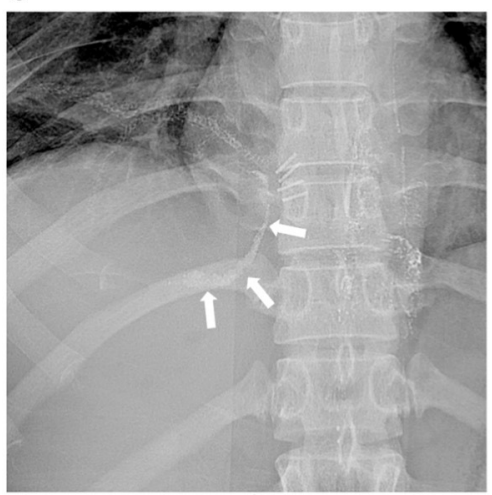

B

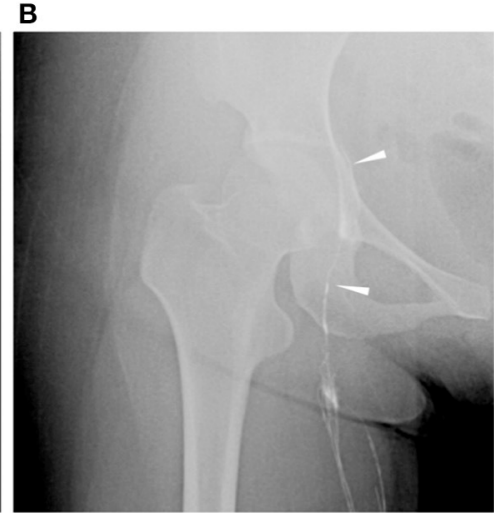

E

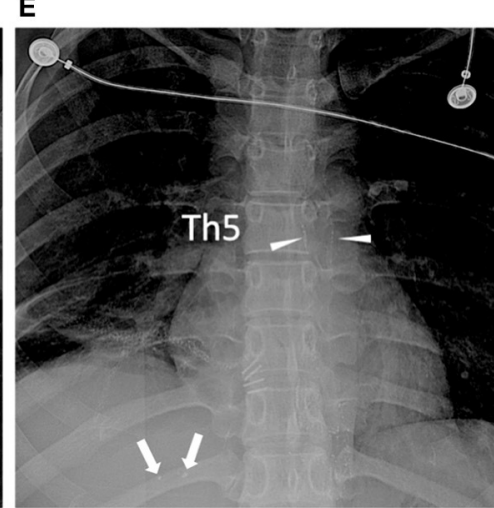

H

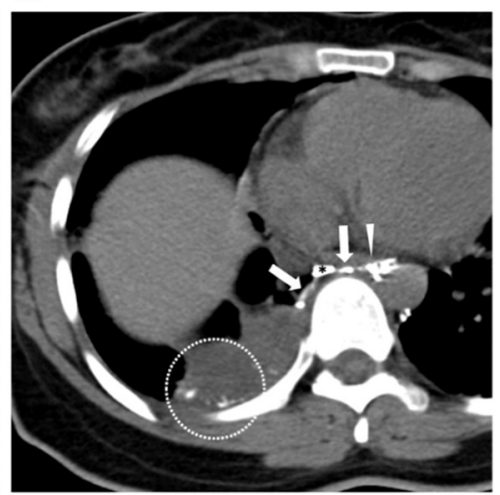

C

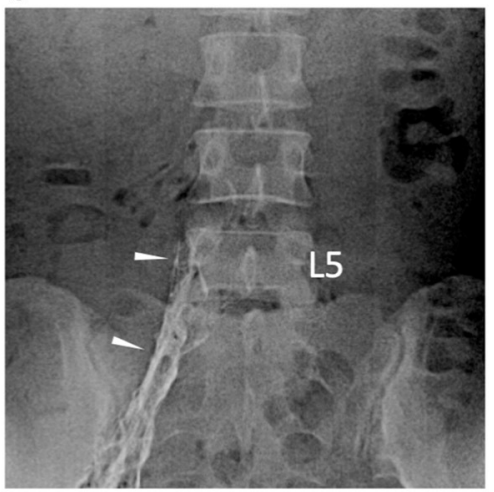

F

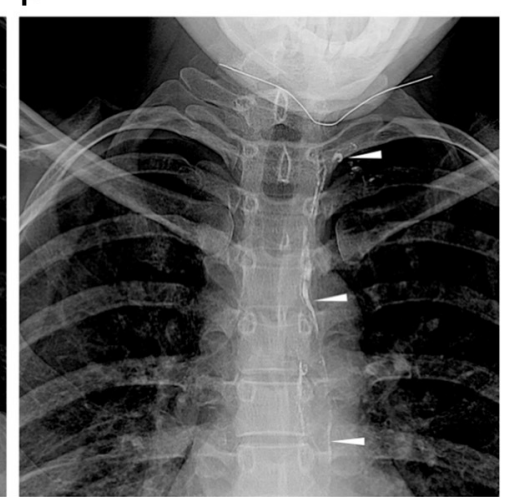

I

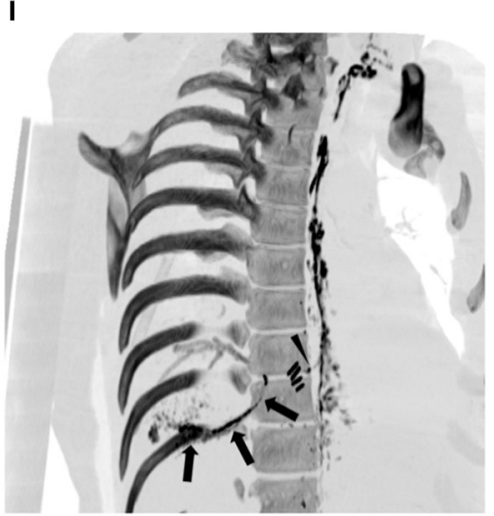

FIGURE 2 | Dynamic opacification of lymphatic vessels in fluoroscopy and chest CT. Images were obtained from the same patient with non-small cell lung carcinoma (Patient ID: 3). (A-F) 3, 9, 22, 45, 52, and 60 min after ethiodized oil injection, respectively, lymphatic vessels (white arrowheads) at the level of knee joint space, upper femoral head, L5, Th12 and Th5 vertebrae, and left jugular venous angle were consecutively opacified and dotted ethiodized oil extravasation [(E) white arrows) can be observed in the course. (G) After completing the ethiodized oil injection $(28.0 \mathrm{ml})$, fluoroscopy demonstrated more definite ethiodized oil extravasation (white arrows). (H) Following CT (axial image with $5 \mathrm{~mm}$ thickness) after TL showed a rupture of the thoracic duct (white arrowhead) near the metal clips (*) and thread-like ethiodized oil extravasation (white arrows) can be observed, as well as the free ethiodized oil in the right pleural effusion (within the white circle). (I) Reconstructed oblique CT image with maximum Intensity projection (MIP) showed more intuitive opacification of the thoracic duct, leakage site (black arrowhead) near the metal clips, and the ethiodized oil extravasation in the right pleural cavity (black arrows). It indicated a possibility of iatrogenic damage to the thoracic duct in the surgery.

pulmonary capillary bed (25). But in patients with comorbidities, such as severe pulmonary dysfunction, pulmonary arteriovenous malformations, and right-to-left shunt heart disease, the ethiodized oil might enter systematic circulation leading to lethal cerebral embolism $(11,25,26)$. So, strict clinical estimation before TL is essential.
Among the 7 patients, the lymphatic duct leakage presenting with definite ethiodized oil extravasation out from thoracic duct and the ectopic presence of the ethiodized oil in the pleural space was identified in $71 \%$ of patients $(5 / 7)$, similar to $64-86 \%$ reported in the literature $(10,14,21,27)$. It implied an iatrogenic injury of the thoracic duct in the 
prior surgeries. Chest CT after TL is routinely performed in our cohort because it has higher diagnostic sensitivity for leakage site identification than fluoroscopy. It can provide more explicitly anatomical details of the lymphatic system (20, 28, 29). If TL treatment fails, these CT data can also assist in planning further lymphatic interventional therapies, such as ALVS mentioned above and thoracic duct embolization $(8,9,11$, 20, 22).

This study has limitations. First, the sample size is minimal. Second, it lacks a comparison to conventional TL with ethiodized oil usage of $<20 \mathrm{ml}$. In the cases with highdose postoperative chylothorax $(>1,000 \mathrm{ml} / \mathrm{d})$, conventional $\mathrm{TL}$ showed a poor efficiency rate of about $35 \%$, so it was rarely solo performed $(5,10)$. Instead, conventional TL with percutaneous lymphatic intervention (e.g., thoracic duct embolization or ALVS) was the optimal choice with a higher efficiency rate of $75-100 \%$ (9). However, by comparing the literature, the results of our study suggest that TL with high-dose ethiodized oil application probably has a better therapeutic effect.

In summary, the results in this preliminary study suggest TL with high-dose ethiodized oil is a feasible, safe, and effective method for treating high-flow postoperative chylothorax. It holds the potential as the secondline choice when conservative treatment fails. Besides, this study works out stable ethiodized oil injection using a commonly used infusion pump, advantaging TL performance.

\section{REFERENCES}

1. Lv S, Wang Q, Zhao W, Han L, Wang Q, Batchu N, et al. A review of the postoperative lymphatic leakage. Oncotarget. (2017) 8:69062-75. doi: 10.18632/oncotarget.17297

2. Inoue M, Nakatsuka S, Yashiro H, Tamura M, Suyama Y, Tsukada J, et al. Lymphatic intervention for various types of lymphorrhea: access and treatment. Radiographics. (2016) 36:2199-211. doi: 10.1148/rg.2016160053

3. Meyer CD, McLeod IK, Gallagher JD. Conservative management of an intraoperative chyle leak: a case report and literature review. Mil Med. (2016) 181:e1180-4. doi: 10.7205/MILMED-D-15-00240

4. Cerfolio RJ, Allen MS, Deschamps C, Trastek VF, Pairolero CP. Postoperative chylothorax. J Thorac Cardiovasc Surg. (1996) 112:1361-5; discussion 1365-6. doi: 10.1016/S0022-5223(96)70152-6

5. Sommer CM, Pieper CC, Itkin M, Nadolski GJ, Hur S, Kim J, et al. Conventional lymphangiography $(\mathrm{CL})$ in the management of postoperative lymphatic leakage (PLL): a systematic review. Rofo. (2020) 192:1025-35. doi: 10.1055/a-1131-7889

6. Gruber-Rouh T, Naguib NNN, Lehnert T, Harth M, Thalhammer A, Beeres $\mathrm{M}$, et al. Direct lymphangiography as treatment option of lymphatic leakage: indications, outcomes and role in patient's management. Eur J Radiol. (2014) 83:2167-71. doi: 10.1016/j.ejrad.2014.09.013

7. Nadolski GJ, Itkin M. Lymphangiography and thoracic duct embolization following unsuccessful thoracic duct ligation: imaging findings and outcomes. J Thorac Cardiovasc Surg. (2018) 156:838-43. doi: 10.1016/j.jtcvs.2018.02.109

8. Pieper CC, Hur S, Sommer CM, Nadolski G, Maleux G, Kim J, et al. Back to the future: lipiodol in lymphography-from diagnostics to theranostics. Invest Radiol. (2019) 54:600-15. doi: 10.1097/RLI.0000000000000578

9. Sommer CM, Pieper CC, Offensperger F, Pan F, Killguss HJ, Koninger J, et al. Radiological management of postoperative lymphorrhea. Langenbecks Arch Surg. (2021) 406:945-69. doi: 10.1007/s00423-021-02094-z

\section{DATA AVAILABILITY STATEMENT}

The raw data supporting the conclusions of this article will be made available by the authors, without undue reservation.

\section{ETHICS STATEMENT}

The studies involving human participants were reviewed and approved by Ethics Committee of Union Hospital, Tongji Medical College, Huazhong University of Science and Technology. The patients/participants provided their written informed consent to participate in this study.

\section{AUTHOR CONTRIBUTIONS}

FP, LL, and XW contributed to the conception, design of the study, and wrote sections of the manuscript. WZ, DL, and LY collected, analyzed, and interpreted the data. All authors contributed to the article and approved the submitted version.

\section{ACKNOWLEDGMENTS}

We are grateful to Prof. Ke Jiang (Union Hospital, Tongji Medical College, Huazhong University of Science and Technology, Wuhan, China) and Dr. Jiazheng Wang (MSC Clinical \& Technical Solutions, Philips Healthcare, Beijing, China) for many valuable suggestions through the formation and design of this work.

10. Alejandre-Lafont E, Krompiec C, Rau WS, Krombach AG. Effectiveness of therapeutic lymphography on lymphatic leakage. Acta Radiol. (2011) 52:30511. doi: 10.1258/ar.2010.090356

11. Pan F, Loos M, Do TD, Richter GM, Kauczor HU, Hackert T, et al. Percutaneous afferent lymphatic vessel sclerotherapy for postoperative lymphatic leakage after previous ineffective therapeutic transpedal lymphangiography. Eur Radiol Exp. (2020) 4:60. doi: 10.1186/s41747-020-00188-9

12. NCCN: National Comprehensive Cancer Network. Non-Small Cell Lung Cancer (Version 5.2021). (2021). Available online at: https://www.nccn.org/ professionals/physician_gls/pdf/nscl.pdf (accessed August 05, 2021).

13. NCCN: National Comprehensive Cancer Network. Esophageal and Esophagogastric Junction Cancers (Version 4.2021). (2021). Available online at: https://www.nccn.org/professionals/physician_gls/pdf/esophageal.pdf (accessed August 05, 2021).

14. Xu KF, Hu XW, Tian XL, Gui YS, Wang L, Li LY, et al. Clinical analysis of 123 cases of chylous effusion. Zhonghua Yi Xue Za Zhi. (2011) 91:464-8. doi: 10.3760/cma.j.issn.0376-2491.2011.07.010

15. Liu DY, Shao Y, Shi XJ. Unilateral pedal lymphangiography with noncontrast computerized tomography is valuable in the location and treatment decision of idiopathic chylothorax. J Cardiothorac Surg. (2014) 9:8. doi: 10.1186/1749-8090-9-8

16. Hill H, Srinivasa RN, Gemmete JJ, Hage A, Bundy J, Chick BJF. Endolymphatic ethiodized oil intranodal lymphangiography and cyanoacrylate glue embolization for the treatment of postoperative lymphatic leak after robot-assisted laparoscopic pelvic resection. J Endourol Case Rep. (2018) 4:66-71. doi: 10.1089/cren.2018.0026

17. Majdalany BS, Khayat M, Downing T, Killoran TP, El-Haddad G, Khaja MS, et al. Lymphatic interventions for isolated, iatrogenic chylous ascites: a multi-institution experience. Eur J Radiol. (2018) 109:41-7. doi: 10.1016/j.ejrad.2018.10.019 
18. Yoshimatsu R, Yamagami T, Miura H, Matsumoto T. Prediction of therapeutic effectiveness according to CT findings after therapeutic lymphangiography for lymphatic leakage. Jpn J Radiol. (2013) 31:797-802. doi: $10.1007 /$ s11604-013-0252-2

19. Kim SW, Hur S, Kim SY, Cho JY, Kwak C, Kim HS, et al. The efficacy of lymph node embolization using n-butyl cyanoacrylate compared to ethanol sclerotherapy in the management of symptomatic lymphorrhea after pelvic surgery. J Vasc Interv Radiol. (2019) 30:195-202 el. doi: 10.1016/j.jvir.2018.09.038

20. Pan F, Loos M, Do TD, Richter GM, Kauczor HU, Hackert T, et al. The roles of iodized oil-based lymphangiography and post-lymphangiographic computed tomography for specific lymphatic intervention planning in patients with postoperative lymphatic fistula: a literature review and case series. CVIR Endovasc. (2020) 3:79. doi: 10.1186/s42155-02000146-x

21. Lee EW, Shin JH, Ko HK, Park J, Kim SH, Sung BK. Lymphangiography to treat postoperative lymphatic leakage: a technical review. Korean J Radiol. (2014) 15:724-32. doi: 10.3348/kjr.2014.15. 6.724

22. Kortes N, Radeleff B, Sommer CM, Bellemann N, Ott K, Richter GM, et al. Therapeutic lymphangiography and CT-guided sclerotherapy for the treatment of refractory lymphatic leakage. J Vasc Interv Radiol. (2014) 25:12732. doi: 10.1016/j.jvir.2013.10.011

23. Iwai T, Uchida J, Matsuoka Y, Kosoku A, Shimada H, Nishide S, et al. Experience of lymphangiography as a therapeutic tool for lymphatic leakage after kidney transplantation. Transplant Proc. (2018) 50:2526-30. doi: 10.1016/j.transproceed.2018.03.095

24. Jardinet T, Veer HV, Nafteux P, Depypere L, Coosemans W, Maleux G. Intranodal lymphangiography with high-dose ethiodized oil shows efficient results in patients with refractory, high-output postsurgical chylothorax: a retrospective study. AJR Am J Roentgenol. (2021) 217:433-8. doi: 10.2214/AJR.20.23465

25. Sheybani A, Gaba RC, Minocha J. Cerebral embolization of ethiodized oil following intranodal lymphangiography. Semin Intervent Radiol. (2015) 32:10-3. doi: 10.1055/s-0034-1396957
26. Geeroms B, Demaerel P, Wauters J, Verschakelen J, Maleux G. Devastating cerebral lipiodol(R) embolization related to therapeutic lymphangiography for refractory chylothorax in a patient with behcet's disease. Vasa. (2018) 47:427-30. doi: 10.1024/0301-1526/a000715

27. Liu D, Xia W, Tang Q, Wang J, Wang M, Zhang C, et al. [Application of lymphography in the location and treatment decision of chyle leakage: an analysis of 177 cases]. Zhonghua Wai Ke $\mathrm{Za}$ Zhi. (2016) 54:281-5. doi: 10.3760/cma.j.issn.0529-5815.2016. 04.008

28. Ginat DT, Sahler LG, Patel N, Saad WA, Waldman LD. Postlymphangiographic computed tomography in chylothorax after esophagogastrectomy: a case report. Lymphology. (2009) 42:130-3.

29. Yamada K, Shinaoka A, Kimata Y. Three-dimensional imaging of lymphatic system in lymphedema legs using interstitial computed tomography-lymphography. Acta Med Okayama. (2017) 71:171-7. doi: 10.18926/AMO/54986

Conflict of Interest: The authors declare that the research was conducted in the absence of any commercial or financial relationships that could be construed as a potential conflict of interest.

Publisher's Note: All claims expressed in this article are solely those of the authors and do not necessarily represent those of their affiliated organizations, or those of the publisher, the editors and the reviewers. Any product that may be evaluated in this article, or claim that may be made by its manufacturer, is not guaranteed or endorsed by the publisher.

Copyright (C) $2021 \mathrm{Li}, \mathrm{Wu}$, Liu, Zhang, Yang and Pan. This is an open-access article distributed under the terms of the Creative Commons Attribution License (CC BY). The use, distribution or reproduction in other forums is permitted, provided the original author(s) and the copyright owner(s) are credited and that the original publication in this journal is cited, in accordance with accepted academic practice. No use, distribution or reproduction is permitted which does not comply with these terms. 